\title{
Impact of Bilateral Breast Cancer on Prognosis: Synchronous Versus Metachronous Tumors
}

\author{
Noha Y Ibrahim ${ }^{1}$, Mahmoud Y Sroor ${ }^{1}$, Dalia O Darwish ${ }^{1 *}$
}

\begin{abstract}
Background: The clinical significance of bilateral breast cancer is unclear and its influence on prognosis is controversial. Materials and Methods: Between 2005 and 2009 we identified 110 cases of bilateral breast cancer (BBC) ; 49 patients had synchronous (duration between the occurrence of carcinoma in both breasts was less than 12 months) and 61 had metachronous (duration was more than one year with no ipsilateral local recurrence). We compared the patient characteristics including age, menopausal status, clinical stage, tumor size, histological classification, lymph node status, and hormone receptor and Her-2 status. We also compared the treatment given and overall and disease free survival (DFS) of both groups. Results: Synchronous cases tend to present more aggressively than metachronous cases and age at first presentation adversely affects survival. The 5 year overall survival was $78.7 \%$ for metachronous and $60 \%$ for synchronous. Patients with positive hormonal status had better five year disease free survival in metachronous compared to synchronous cases, at $76 \%$ and $63 \%$, respectively. Age at first presentation $>45$ years had better DFS $(65 \%)$ compared to those with age $\leq 45$ years $(52 \%)$ at 5 years follow up. Conclusions: Patients with synchronous breast cancer may have worse prognosis. Young age and hormone receptor negative were risk factors in our study. Close follow up and early detection of contralateral breast cancer is mandatory.
\end{abstract}

Keywords: Bilateral breast cancer - synchronous - metachronous - survival - prognosis.

Asian Pac J Cancer Prev, 16 (3), 1007-1010

\section{Introduction}

The risk of bilateral breast cancer has risen recently as a result of increase in life expectancy of breast cancer patients due to improvement in early diagnosis and therapy (Hartman et al., 2007). The incidence of BBC is reported to range from 2 to $12 \%$ (Carmichael et al., 2002).

There is uncertainty whether developing a contralateral tumour influences the outcome as some studies suggest poor survival while others report similar survival compared to unilateral disease. Women diagnosed with breast cancer are at increased risk of developing contralateral breast tumor, two to six times greater than developing a first breast cancer in general population (Heron et al., 2000).

Bilateral breast cancer may be diagnosed in both breasts at the same time (Quan et al., 2008) (synchronous) or may occur after a time interval varying between one year up to 5 years (metachronous) (Kheirelseid et al., 2011).

Risk factors for the development of bilateral breast cancer include family history of breast cancer, initial tumor diagnosed at an early age, lobular histology of the first tumor, treatment received for the first tumor, small size and early stage at diagnosis, receptor status and Her-2/neu positive patients (Vuoto et al., 2010; Chen et al., 2013;
Tsyhyka et al., 2013).

The impact of bilateral breast cancer on survival for the patients is still controversial. The aim of the study is to describe the characteristics of patients suffering from bilateral breast cancer and to analyze its impact on survival.

\section{Patients and methods}

Between June 2005 and July 2009 patients with bilateral breast cancer were collected retrospectively. A total of 110 female patients were collected from Kasr Al Ainy oncology centre and Nasr institute. The synchronous bilateral breast cancer ( 49 cases) was diagnosed within one year from the primary breast cancer. Patients diagnosed after this period were considered metachronous (61 cases). Patients with metastatic tumor at diagnosis were excluded. The incidence of bilateral breast cancer was $2.7 \%$ (110 patients out of 4008 patients with breast cancer).

The diagnosis of contralateral breast cancer was verified by pathological biopsy or cytology. In metachronous breast cancer patients we used the age at second presentation as the reference age.

We compared the patient characteristics including; age, menopausal status, clinical stage, tumor size, histological classification (patient with synchronous is considered 
mixed if both breasts do not have the same histological diagnosis), lymph node status, hormone receptor and Her-2 status. Disease-free survival was calculated as the number of months from the diagnosis of the initial tumor to recurrence (local and distant), death or last follow-up. All patients were treated according to local protocols and followed up every 3 months for 1 year, 6 months for 2 years and then annually. Annual mammography was done to all patients. We also compared the treatment given and outcome of both groups.

\section{Statistical analysis}

Data were statistically described in terms of range, mean \pm standard deviation $( \pm \mathrm{SD})$, median, frequencies and percentages. Kaplan-Meier survival for different parameters was done. A probability value ( $\mathrm{P}$ value) less than 0.05 was considered statistically significant. All statistical calculations were done using computer programs Microsoft Excel 2003 (Microsoft Corporation, NY, USA) and SPSS (Statistical Package for the Social Sciences; SPSS Inc., Chicago, IL, USA) version 15 for Microsoft Windows.

\section{Results}

Bilateral breast cancer was diagnosed in 110 cases out of 4008 breast cancer case $(2.7 \%), 61$ patients $(55.5 \%)$ were metachronous and $49(44.5 \%)$ were synchronous. The Patient characteristics of bilateral breast cancer patients were demonstrated in Table 1.

The tumor was detected during screening in $10 \%$ of the initial cases (11 patients) compared to $64.5 \%$ of the contralateral tumors. For initial tumors $28.2 \%$ were detected by mammography compared to $64.5 \%$ of contralateral tumors. Two cases $(1.8 \%)$ of contralateral tumors required MRI for diagnoses (Table 2).

The 5 year overall survival was $78.7 \%$ for metachronous and $60 \%$ for synchronous ( $\mathrm{p}=0.02$ ) (Figure 1 ). The median time for the diagnoses of both tumors in metachronous cases was 36.5 months (range 13-60 months). Shorter disease free interval was associated with worse overall survival.

Positive hormone receptor was $61.3 \%$ in synchronous and in metachronous was $67.2 \%$ and $75.4 \%$ in first and second breast respectively however it was not significant. Her-2 status was $30.6 \%$, in synchronous and $29.5 \%$ and $32.7 \%$ in first and second metachronous breasts respectively but it was not statistically significant. Patients with positive hormonal status had better five years disease free survival in metachronous compared to synchronous cases, $76 \%$ and $63 \%$ respectively $(\mathrm{p}=0.10)$. Hormone receptor negative patients had worse disease free survival in five years for both groups $48 \%$ and $42 \%$ respectively $(\mathrm{p}=0.55)$.

The disease free survival for all patients showed drop at one year due to the metastatic and local recurrent cases, then showed a second drop at 2 years and then after 5 years. The disease free survival between both groups was worse for the synchronous cases due to more aggressive presentation and younger age yet it was not statistically significant (Figure 2).
Table 1. Demographic and Histopathologic Characteristics of BBC Patients.

\begin{tabular}{|c|c|c|c|c|}
\hline \multicolumn{2}{|c|}{ Characteristic Synchronous } & \multirow{2}{*}{\multicolumn{2}{|c|}{$\begin{array}{r}\text { Metachronous } \\
\mathrm{N}=61,(55.5 \%)\end{array}$}} & \multirow[t]{3}{*}{$P$ value } \\
\hline \multirow[t]{2}{*}{ Number } & \multirow{2}{*}{$\mathrm{N}=49,(44.5 \%)$} & & & \\
\hline & & \multicolumn{2}{|c|}{${ }^{1 \text { st }}$ presentation ${ }^{2 n d}$ presentation } & \\
\hline Age & $44.2 \pm 11.2$ & $42.9 \pm 6.3$ & $48.6 \pm 9.5$ & 0.093 \\
\hline \multicolumn{5}{|c|}{ Menopausal status } \\
\hline Pre & $26(53 \%)$ & $40(65.6 \%)$ & $12(19.7 \%)$ & \multirow[t]{2}{*}{0.473} \\
\hline Post & $23(47 \%)$ & $21(34.4 \%)$ & $49(80.3 \%)$ & \\
\hline \multicolumn{5}{|l|}{ Clinical stage } \\
\hline I & $6(12.2 \%)$ & $4(6.6 \%)$ & $5(8.2 \%)$ & \multirow{3}{*}{0.0001} \\
\hline II & $14(28.6 \%)$ & $41(67.2 \%)$ & $45(73.8 \%)$ & \\
\hline III & $29(59.2 \%)$ & $16(26.2 \%)$ & $11(18 \%)$ & \\
\hline \multicolumn{5}{|l|}{ Tumor size } \\
\hline$\leq 2 \mathrm{~cm}$ & $7(14.3 \%)$ & $4(6.6 \%)$ & $7(11.5 \%)$ & \multirow[t]{2}{*}{0.598} \\
\hline$>2 \mathrm{~cm}$ & $42(85.7 \%)$ & $57(93.4 \%)$ & $54(88.5 \%)$ & \\
\hline \multicolumn{5}{|c|}{ Histological calcification } \\
\hline Duct & $32(65.3 \%)$ & $51(83.6 \%)$ & $52(85.2 \%)$ & \multirow[t]{3}{*}{0.15} \\
\hline Lobular & $13(26.5 \%)$ & $10(16.4 \%)$ & $9(14.8 \%)$ & \\
\hline Mixed & $4(8.2 \%)$ & - & - & \\
\hline \multicolumn{5}{|c|}{ Lymph node status } \\
\hline Positive & $42(85.7 \%)$ & $52(85.2 \%)$ & $50(82 \%)$ & \multirow[t]{2}{*}{0.834} \\
\hline Negative & $7(14.3 \%)$ & $9(14.8 \%)$ & $11(18 \%)$ & \\
\hline \multicolumn{5}{|c|}{ Hormone receptor } \\
\hline Positive & $30(61.3 \%)$ & $41(67.2 \%)$ & $46(75.4 \%)$ & \multirow[t]{3}{*}{0.1} \\
\hline Negative & $13(26.5 \%)$ & $12(19.7 \%)$ & $10(16.4 \%)$ & \\
\hline Unknown & $6(12.2 \%)$ & $8(13.1 \%)$ & $5(8.2 \%)$ & \\
\hline \multicolumn{5}{|l|}{ Her-2 status } \\
\hline Positive & $15(30.6 \%)$ & $18(29.5 \%)$ & $20(32.7 \%)$ & \multirow[t]{3}{*}{0.75} \\
\hline Negative & $24(48.9 \%)$ & $31(50.8 \%)$ & $32(52.5 \%)$ & \\
\hline Unknown & $10(20.4 \%)$ & $12(19.7 \%)$ & $9(14.8 \%)$ & \\
\hline \multicolumn{5}{|c|}{ Adjuvant chemotherapy } \\
\hline Yes & $44(89.8 \%)$ & $51(83.6 \%)$ & $55(90 \%)$ & \multirow[t]{2}{*}{0.722} \\
\hline No & $5(10.2 \%)$ & $10(16.4 \%)$ & $6(10 \%)$ & \\
\hline \multicolumn{5}{|c|}{ Adjuvant radiotherapy } \\
\hline Yes & $26(53 \%)$ & $55(90 \%)$ & $39(64 \%)$ & \multirow[t]{2}{*}{0.001} \\
\hline No & $23(47 \%)$ & $6(10 \%)$ & $22(36 \%)$ & \\
\hline
\end{tabular}

Table 2. Diagnosis of Bilateral Breast Cancer-First Breast Versus Second Breast.

\begin{tabular}{|c|c|c|}
\hline Variable & 1stbreast & 2ndbreast \\
\hline \multicolumn{3}{|l|}{ Presentation } \\
\hline Symptomatic & $99 \quad(90 \%)$ & $39(35.5 \%)$ \\
\hline Screening & $11(10 \%)$ & $71(64.5 \%)$ \\
\hline \multicolumn{3}{|c|}{ Mode of detection } \\
\hline Clinical & $74(67.2 \%)$ & $44 \quad(40 \%)$ \\
\hline $\mathrm{U} / \mathrm{S}$ & $5(4.6 \%)$ & $4(3.6 \%)$ \\
\hline Mammogram & $31(28.2 \%)$ & $60(54.6 \%)$ \\
\hline MRI & $0 \quad(0 \%)$ & $2(1.8 \%)$ \\
\hline
\end{tabular}

Table 3. Presentation of Metachronous Breast Cancer Patients as Regards the Size of the Breast Mass.

\begin{tabular}{ccc}
\hline Tumor size & ${ }^{1 \text { st }}$ presentation & ${ }^{2 n d}$ presentation \\
\hline$\leq 2 \mathrm{~cm}$ & 4 & 7 \\
$3 \mathrm{~cm}$ & 26 & 30 \\
$4 \mathrm{~cm}$ & 21 & 20 \\
$\geq 5 \mathrm{~cm}$ & 10 & 4 \\
\hline
\end{tabular}

Comparing the disease free survival for all cases as regards age at first presentation it was found that patients whose age at first presentation $>45$ years have better disease free survival $(65 \%)$ compared to those with age $\leq 45$ years $(52 \%)$ at 5 years follow up $(\mathrm{p}=0.01)$ which is attributed to the young patients with synchronous breast 


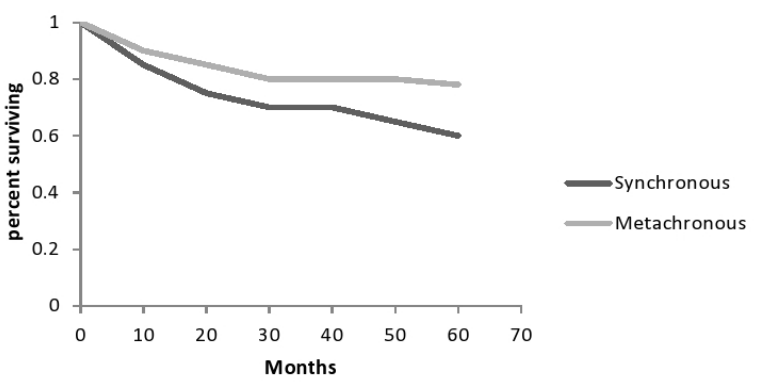

Figure 1. Overall Survival for the Two Groups

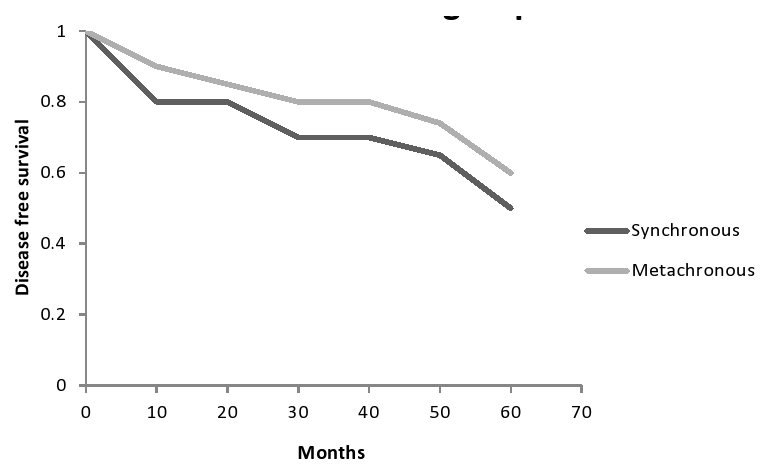

Figure 2. Kaplan Meier Disease-free Survival Plot for the Two Groups.

cancer presenting with aggressive advanced stage.

Upon analysis of patients with metachronous breast cancer, the primary breast was mainly presented at early stage (73.2\% were stages I and II versus $40.8 \%$ in synchronous cases). Moreover, on analysis of these patients as regards the size of the breast mass we found that the second breast cancer was diagnosed at a smaller size which may indicate some awareness of the patients and proper clinical examination as well as the importance of regular follow up and annual mammography (Table 3).

\section{Discussion}

The incidence of $\mathrm{BBC}$ is variable but still low with a debate on its impact on survival. In our study of bilateral breast cancer patients $44.5 \%$ were synchronous and $55.5 \%$ were metachronous with a 5 year overall survival of $60 \%$ and $78.7 \%$ respectively. The short time interval for diagnosis of $\mathrm{BBC}$ was correlated with worse prognosis.

This was in accordance with Vuoto et al. (2010) who detected BBC in $7.98 \%$ of breast cancer cases with a higher incidence of metachronous versus synchronous, $58.8 \%$ and $41.2 \%$ respectively. This study also showed a higher survival for metachronous $94.6 \%$ versus $63.3 \%$ for synchronous carcinoma (Vuoto et al., 2010). Another study was conducted in Australia and New Zealand to investigate synchronous breast cancer among 35,370 cases of early stage breast cancer. It showed the risk of synchronous breast cancer to be $2.3 \%$ with an equivocal or moderately poorer survival (Roder et al., 2013). This was similar to the incidence in our study.

In the present study, positive hormone receptor status was less in the synchronous compared to first and second metachronous $(61.3 \%, 67.2 \%$ and 75.4 respectively). These results were comparable to Tsyhyka et al. (2013) where hormone receptor was positive in $67 \%$ of synchronous cases and 73.7 and 66.7 in first and second metachronous breast (Tsyhyka et al., 2013). Her-2 status was similar in both groups with slight high tendency in synchronous $30.6 \%$ compared to $29.5 \%$ and $32.7 \%$ in first and second metachronous BBC respectively. This was comparable to Baykara et al. (2012), where the HER2 status of patients for 1st and 2nd breast in synchronous tumors was $13.3 \%$ and $28.6 \%$, and in metachronous tumors, $41.7 \%$ and $37.5 \%$, respectively (Baykara et al., 2012).

In a Chinese study analyzing the data of 190 cases of bilateral breast cancer, the peak age of onset of the first metachronous BBC was significantly younger than the synchronous tumors $(\mathrm{p}=0.001)$. Hormone receptor positivity was correlated more with the first and second synchronous BBC compared to the metachronous BBC. Extra capsular extension and ER positive $(\mathrm{p}=0.008)$ tend to have synchronous while HER $3+(\mathrm{p}=0.001)$ tend to have metachronous. The prognosis was better for the metachronous BBC (Liang et al., 2013).

Patient with positive hormonal status had better disease free survival in metachronous compared to synchronous cases. This coincides with Tsyhyka et al. (2013) showing more aggressive clinical course for synchronous BBC cancer with significant impact of hormonal status on overall and progression free survival. Patients with metachronous breast cancer had overall and progression free survival of $92.2 \%$ and $71.3 \%$ in three and five years respectively, while those with synchronous had $64.2 \%$ and $48.2 \%$ respectively (Tsyhyka et al., 2013).

The disease free survival at 5 years follow up was statistically significant better for patients with age $>45 y e a r s$ at first presentation $(\mathrm{p}=0.01)$. This is attributed to the young patients with synchronous breast cancer first presenting with aggressive advanced stage. Numerous studies have found that patients with BBC were significantly younger at the time of diagnosis of their initial cancer and considered age as the most important predictor for contralateral breast cancer. The earlier a woman develops a first breast cancer, the higher the risk of developing a contralateral tumor (Baykara et al., 2012; Liang et al., 2013).

The study was limited by the small number of patients and the absence of genetic studies for these cases. This was due to limited resources in developing countries.

In conclusion, we conclude from this study that patients with synchronous breast cancer may have worse prognosis than metachronous. young age and hormone receptor negative were risk factors in our study. close follow up and early detection of contralateral breast cancer should not be limited to clinical examination, and mammographic screening is mandatory. proper social and educational care is needed to verify the concept of malignant disease to these patients for early detection of a second malignancy. further studies are needed to verify the aggressiveness of synchronous breast cancer and to identify whether it is a risk factor.

\section{References}

Hartman M, Czene K, Reilly M, et al (2007). Incidence and 
Noha Y Ibrahim et al

prognosis of synchronous and metachronous bilateral breast cancer. J Clin Oncol, 25, 4210-16.

Carmichael AR, Bendall S, Lockerbie L, et al (2002). The long-term outcome of synchronous bilateral breast cancer is worse than meta-chronous or unilateral tumours. Eur $J$ Surg Oncol, 28, 388-91.

Heron DE, Komarnicky LT, Hyslop T, et al (2000). Bilateral breast carcinoma: risk factors and outcomes for patients with synchronous and metachronous disease. Cancer, $\mathbf{8 8}$, 2739-50.

Quan G, Pommier SJ, Pommier RF (2008) Incidence and outcomes of contralateral breast cancers. Am J Surg, 195, 645-50.

Kheirelseid E A H, Jumustafa H, Miller N, et al (2011). Bilateral breast cancer: analysis of incidence, of survival and disease characteristics. Breast Cancer Res Treat, 126, 131-40.

Tsyhyka DY, Hotko YS and Devinyak (2013). Receptor status of tumor as prognostic factor in patients with bilateral breast cancer. Exp Oncol, 35, 291-4.

Chen SF, Du CW, Yang P, et al (2013). The molecular and clinicopathologic characteristics of bilateral breast cancer. Scientific reports/3:2590/DOI, 10, 1038.

Vuoto HD, Garcia AM, Candas GB, et al (2010). Bilateral breast carcinoma: clinical characteristics and its impact on survival. Breast J, 6, 625-32.

Roder D, et al (2013). Survival from synchronous bilateral breast cancer: The experience of surgeons participating in the breast audit of the society of breast surgeons of Australia and New Zealand. Asian Pacific J Cancer Prev, 13, 4571-5.

Baykara M, Ozturk SC, Buyukberber S, et al (2012). Clinicopathological features in bilateral breast cancer. Asian Pacific J Cancer Prev, 13, 4571-5.

Liang X, Li D, Geng W, Cao X, et al (2013). The prognosis of synchronous and metachronous bilateral breast cancer in Chinese patients. Tumor biology, 2, 995-1004. 